\title{
Acute Toxicity of The Pharmaceutical Substance Branched Oligohexamethyleneguanidine Hydrochloride at Mice and Rats after Intragastric Administration
}

\author{
Denis 0 Shatalov ${ }^{1,2}$, Stanislav A Kedik ${ }^{1,2}$, Natalia V Krupenchenkova ${ }^{1}$, Elizaveta A Voroshilova ${ }^{1 *}$, \\ Ivan S Ivanov ${ }^{1,2}$ and Diana A Akhmedova ${ }^{1}$ \\ ${ }^{1}$ MIREA-Russian Technological University, Moscow, Russia
}

${ }_{2}^{2}$ Institute of Pharmaceutical Technologies, Moscow, Russia

*Corresponding author: Elizaveta Voroshilova, MIREA-Russian Technological University, Moscow, Russia.

To Cite This Article: Elizaveta Voroshilova. Acute Toxicity of The Pharmaceutical Substance Branched Oligohexamethyleneguanidine Hydrochloride at Mice and Rats after Intragastric Administration. Am J Biomed Sci \& Res. 2019 - 4(2). AJBSR.MS.ID.000766.

DOI: 10.34297/AJBSR.2019.04.000766

Received: June 26, 2019 | Published: July 18, 2019

\begin{abstract}
The toxicity of pharmaceutical substances remains one of the main issues of modern research. Accordingly, the search for analogues with lowered toxicity as compared to established substances remains a major task for modern pharmacology. A promising compound in this respect is OHMG-HCl, the toxicity of which is examined in this study. The results of the study indicate that the application of OHMG- $\mathrm{HCl}$ to be a promising perspective due to its low toxicity.
\end{abstract}

Keywords: Toxicity; Toxicology; OHMG-HCl; Branched oligohexamethyleneguanidine hydrochloride; Acute toxicity.

Abbrevations: OHMG-HCl: Oligohexamethyleneguanidine Hydrochloride; JSC: Joint-Stock Company

\section{Introduction}

The excipient OHMG-HCl is a branched oligohexamethyleneguanidine hydrochloride and also is a synthetic high molecular weight derivative of guanidine [1-3]. Currently, the promising substances are poly guanidines-synthetic high-molecular derivatives of a specific nitrogen base-guanidine. Distributed in nature, have high efficiency and long-term biocidal effect, so that poly guanidines are widely used in agriculture as preservatives for seeds of agricultural plants, in medicine and veterinary medicine as antimicrobial drugs [4-8]. Due to their wide spectrum of antimicrobial activity combined with low toxicity, guanidine derivatives are already for a long time established as active substances in many antiseptics. Drugs based on polyhexamethylene guanidium salts keep in their activity in a wide range of environmental conditions, easy solve in a water and prevent the formation of microbial biofilms $[1,9,10]$.

The mechanism of the antimicrobial action of polyguanidines is based on the destruction of ester bonds in the lipids and lipopolysaccharide complexes of microbial cell membranes, which initially leads to the repression of aggression factors (plasmacoagulases, hyaluronidase, oxidation of SH-groups of glycolytic enzymes) and forthcoming death of infectious agents [9]. Polyguanidines are able to sharp movement to the surface of the bacterial cell due to electrostatic interactions and then disturb its integrity by replacing of metal cations $[9,10]$. Due to the widespread development of antibiotic resistance among microorganisms, the antiseptic drugs are particular importance for the treatment of ubiquitous acute and chronic infections of the oral cavity and throat, such as tonsillitis, pharyngitis, laryngitis and periodontal diseases [11]. Among the most common pathogens of the aerobic microbiota are Streptococcus spp., H. influenzae, M. catarrhalis, S. aureus, N. gonorrhoeae, Candida spp [4,10,12]. It is believed that OHMG-HCl, as other polyguanidines, has a low level of toxicity in comparing with non- branched oligohexamethylene guanidine hydrochloride. Accordingly, the objective of this study is to detect acute toxicity and determine the toxicity class. 


\section{Materials and Methods}

\section{Chemicals}

The studied compound is the pharmaceutical substance "branched oligohexamethylene guanidine hydrochloride" (produced in JSC «Institute of Pharmaceutical Technologies» (IPT), Russia).

\section{Test system}

The realization of the established objective was only possible with the use of experimental animals, since animal research provides the most complete data on the toxicity of a given drug. In toxicological research the standard subjects are mice and rats. The experiment was performed on outbred mice (males and females) with a starting weight of 25-30 g and on outbred rats, with a starting weight of 300-350 g for males and 210-260 g for females. Each animal was designated with an individual paint mark. The animals were selected and divided into groups by weight and age so that the mass of each animal would not deviate from the group average by more than $20 \%$.All actions with the animals were performed according to the rules of the European Convention for the Protection of Vertebrate Animals Used for Experimental and other Scientific Purposes (ETS 123) Strasbourg, 1986.

\section{Method of administration, choice of doses, and drug preparation for administration}

During the study was used method of intragastric administration, to study the substance's toxicity in systemic application. In a preliminary test on both mice and rats the animals received intragastric doses of $5 \mathrm{mg} / \mathrm{kg}, 200 \mathrm{mg} / \mathrm{kg}$, and $800 \mathrm{mg} / \mathrm{kg}$. Animal death was established at the $800 \mathrm{mg} / \mathrm{kg}$ dose. Accordingly, in the main experiment the administered doses amounted to 200 $\mathrm{mg} / \mathrm{kg}, 400 \mathrm{mg} / \mathrm{kg}, 600 \mathrm{mg} / \mathrm{kg}$, and $800 \mathrm{mg} / \mathrm{kg}$.

\section{Results and Discussion}

This study on the acute toxicity of branched oligohexamethyleneguanidine hydrochloride performed on outbred mice and rats of both sexes showed that upon one-time intragastric administration the substance has a dose-dependent toxic effect to the animal. The median lethal dose amounted to 417 $\mathrm{mg} / \mathrm{kg}$ for male mice, $490 \mathrm{mg} / \mathrm{kg}$ for female mice, $501 \mathrm{mg} / \mathrm{kg}$ for male rats, and $457 \mathrm{mg} / \mathrm{kg}$ for female rats. In the case of mice it was noticed the influence of subtoxic doses of the studied substance on body weight mass decreasing. However, upon autopsy there were no observed remaining signs of intoxication or pathological changes in the structures of internal organs. Morphometric analysis showed decreasing of the relative weight of the thymus and spleen.
Female rats receiving a dose of $400 \mathrm{mg} / \mathrm{kg}$ showed the increasing of the relative weight of the liver and brain.

\section{Conclusion}

Based on obtained data the studied substance was attributed to the IV class of the low toxicity substance $(301-2000 \mathrm{mg} / \mathrm{kg}$ in intragastric administration) (Classes of toxicity of substances in accordance with the modified classification of the Organization for Economic Cooperation and Development).

\section{Acknowledgement}

This research was funded by Ministry of Science and Higher Education of the Russian Federation, grant number 14.N08.12.0095.

\section{References}

1. Kedik SA (2011) Structure and molecular-weight characteristics of oligo(hexamethyleneguanidine) hydrochlorides. Pharmaceutical Chemistry Journal 44(10): 568-573.

2. Kedik SA, Sedishev IP, Panov AV (2012) Branched oligomers on the basis of a guanidine derivative and disinfecting agent containing said oligomers (alternatives).

3. Kedik SA (2014) Development and validation of the method to control guanidine hydrochloride monomer impurities in pharmaceutical substance "branched oligohexamethyleneguanidine hydrochloride". Vestnik MITHT 9(2): 32-36.

4. Asyamova AV, Gerunov VI (2017) Guanidine derivatives in medicine and agriculture. FSBEI HE Omsk State Agrarian University named after P.A. Stolypin. 4(28): 130-135.

5. Kudinov PI (2006) Research of ecological safety of technology of conservation of sunflower seeds by guanidine derivatives. Izvestiya vuzov. Pishevaya technologia 6: 89-90.

6. Cha Kam An (2013) Comparative in vitro Antibacterial Activity of Polyhexamethylene Guanidine Hydrochloride and Polyhexamethylene Guanidine Succinate. Antibiot Khimioter 58(1-2): 3-7.

7. Hyemin Choia (2017) Antifungal activity of the cationic antimicrobial polymer-polyhexamethylene guanidine hydrochloride and its mode of action. Fungal Biology 121(1): 53-60.

8. Moore LE (2008) In vitro study of the effect of cationic biocides on bacterial population dynamics and susceptibility. Appl Environ Microbiol 74(15): 4825-4834.

9. Vointseva II, Gembitsky PA (2009) Polyguanidines-disinfectants and polyfunctional additives. LKM- press. 304 Russian.

10. Shatalov DO (2017) The Current State and Development of Perspectives of Application of Synthetic Antimicrobial Agents. Polymer science, Series D 3(10): 293-299.

11. Shatalov DO (2018) The diseases of the oral cavity: treatment options and prospects for the creation of effective drugs. Problems of biological, medical and pharmaceutical chemistry 21(3): 11-16.

12. Alekseev KV (2011) Polymers for pharmaceutical technology: training manual Moscow, Russia. 